\title{
SYSTEMATIC EVALUATION OF MICROSTRUCTURAL EFFECTS ON THE MECHANICAL PROPERTIES OF ATI 718PLUS ${ }^{\circledR}$ ALLOY
}

\author{
R.M. Kearsey ${ }^{1}$, J. Tsang ${ }^{1}$, P. Au ${ }^{1}$, S. Oppenheimer ${ }^{2}$ and E. McDevitt ${ }^{2}$ \\ ${ }^{1}$ Structures and Materials Performance Laboratory \\ Institute for Aerospace Research \\ National Research Council of Canada \\ Ottawa, ON, Canada \\ ${ }^{2}$ ATI Allvac \\ 2020 Ashcraft Avenue, Monroe, NC \\ USA, 28110
}

Keywords: ATI 718Plus ${ }^{\circledR}$ Alloy, creep-fatigue, LCF, FCGR, Dwell FCGR

\begin{abstract}
Four microstructural variants of ATI 718Plus ${ }^{\circledR}$ Alloy (718Plus) are produced via modified heat treatments to elucidate the effects of grain size, precipitate size, morphology, and phase fraction ( $\delta$ and $\gamma^{\prime}$ ), on the mechanical properties of low cycle fatigue (LCF) life, fatigue crack growth rate (FCGR) properties, and Dwell FCGR behaviour at both $649^{\circ} \mathrm{C}\left(1200^{\circ} \mathrm{F}\right)$ and $704^{\circ} \mathrm{C}\left(1300^{\circ} \mathrm{F}\right)$ under 100s dwell and non dwell conditions. Similar tests are also performed on Waspaloy in two comparative microstructural conditions. FCGR results show that at both test temperatures, all microstructural conditions of 718Plus and Waspaloy exhibit identical behavior in the steady state regime, except that 718 Plus exhibits a much higher threshold stress intensity $\left(\Delta \mathrm{K}_{\mathrm{TH}}\right)$. However, the Dwell FCGR results show that Waspaloy displays better steady state crack growth resistance under dwell conditions; with an optimized precipitate microstructure of 718Plus showing considerable improvement. LCF test results demonstrate that all four microstructural conditions of 718Plus have superior life compared to Waspaloy under all test conditions.
\end{abstract}

\section{Introduction}

Recently there has been a rising interest by gas turbine manufacturers in the use of 718Plus for structural and critical rotating components in both aero and industrial power generation applications. This is primarily due to the alloy's proven higher temperature capability over the widely used gas turbine material, alloy 718 [i]. Alloy 718 has a proven track record as a moderate temperature superalloy in the aerospace industry due to its remarkable combination of high strength and excellent processing features [ii]. However, it is primarily strengthened by the metastable $\gamma^{\prime \prime}$ precipitate phase, thereby limiting its upper temperature capability due to associated losses in tensile and creep strength upon the $\gamma^{\prime \prime}$ to $\delta$ phase equilibrium transformation that occurs at $649^{\circ} \mathrm{C}\left(1200^{\circ} \mathrm{F}\right)$ given sufficient time [iii]. New engine designs, and optimization of existing legacy engines, have placed higher operating temperature and strength demands on component materials to meet improved turbine efficiency criteria. Careful compositional selection of 718Plus has provided the means to surpass the $\gamma^{\prime \prime}$ temperature limitation of alloy 718 by incorporating the structurally stable $\gamma^{\prime}$ phase as its main strengthening agent and thereby increasing its operating range to as high as $700^{\circ} \mathrm{C}\left(1292^{\circ} \mathrm{F}\right)$. The added advantage to using 
718 Plus over existing "650 plus" superalloys such as Waspaloy and alloy 720 , is that it has a lower raw material cost, demonstrated better processing characteristics, and suitable long-term thermal stability.

Although affordability and long-term phase stability are key requirements for these alloys in turbine applications, significant resistance to loading under static, cyclic and creep conditions is also vital to ensure longer and safer component life. Hence, critical high temperature mechanical properties such as LCF life, FCGR behaviour, and creep-fatigue resistance must also be optimized and characterized prior to engine implementation. In this study, four microstructural variants of the 718Plus alloy are produced via modified heat treatments to elucidate the effects of grain size, precipitate size and morphology, as well as relative phase fraction, on mechanical properties.

\section{Materials}

\section{Experimental Materials and Test Methods}

The 718Plus material used in this study was removed from a single VIM/VAR heat that was converted to a $13.7 \mathrm{~cm}$ (5.4 in) final diameter billet. The Waspaloy material was produced in a similar manner being converted to a final billet diameter of $14.9 \mathrm{~cm}$ (5.9 in). The nominal compositions of each alloy are shown in Table I. Both billet materials were subsequently sectioned into specimen blanks and thermally processed to achieve four different material conditions for 718Plus and two different conditions for Waspaloy. All sample materials used for microstructural and mechanical testing were removed from the mid-radius region of each billet.

Table I: Nominal alloy compositions for 718Plus and Waspaloy used in this study (wt.\%).

\begin{tabular}{lcccccccccccc}
\hline Alloy & $\mathrm{Ni}$ & $\mathrm{Co}$ & $\mathrm{Cr}$ & $\mathrm{Fe}$ & $\mathrm{Ti}$ & $\mathrm{Al}$ & $\mathrm{Nb}$ & $\mathrm{Mo}$ & $\mathrm{W}$ & $\mathrm{C}$ & $\mathrm{P}$ & $\mathrm{B}$ \\
\hline \hline 718Plus ${ }^{\circledR}$ & 51.95 & 8.99 & 17.81 & 9.59 & 0.75 & 1.49 & 5.52 & 2.71 & 1.01 & 0.022 & 0.0056 & 0.0044 \\
Waspaloy & 51.95 & 13.35 & 19.58 & 0.91 & 3.05 & 1.38 & 0.02 & 4.18 & 0.04 & 0.036 & 0.0018 & 0.0073 \\
\hline
\end{tabular}

Heat treatment details for the various material conditions of 718Plus and Waspaloy are provided in Table II. The conditions being investigated include (HT1) the standard heat treatment condition, which retains the fine equiaxed grain structure $(\sim 25-60 \mu \mathrm{m})$, a $\gamma^{\prime}$ phase fraction between 19-21 wt.\% with a near-spherical precipitate size of $\sim 30 \mathrm{~nm}$, and a small rod like $\delta$ phase fraction of 6-7 wt.\% primarily along the grain boundaries. The second microstructural condition (HT2) is incorporated to study the effects of extensive thermal exposure on mechanical properties and is achieved by using the standard heat treatment plus a high temperature soak at $732^{\circ} \mathrm{C}\left(1350^{\circ} \mathrm{F}\right)$ for $1000 \mathrm{hrs}$. The third microstructural condition (HT3) entails applying a presolution heat treatment step for reduction in notch sensitivity by purposely precipitating and modifying the grain boundary $\delta$ phase. The last microstructural condition (HT4) incorporates both the pre-solution and standard heat treatment steps with an additional precipitate overaging step to elucidate the effect of increased precipitate size on mechanical properties. In addition, comparative mechanical testing is also performed on Waspaloy in the standard heat treatment (W1) and thermally exposed (W2) material conditions.

\section{Microstructural Properties}

The typical variation in grain structure for both billets is shown in Figure 1, illustrating uniform equiaxed grain morphology in all three dimensions for 718Plus and Waspaloy. For the samples inspected, 718Plus showed a slightly larger variation in grain size compared to Waspaloy. Higher magnification images, provided in Figure 2, show the presence of the incoherent $\delta$ phase precipitates primarily decorating grain boundaries with negligible precipitate levels at 
intragranular or twin boundaries sites. Shown in Figure 3 is the typical rod-shaped morphology of the orthorhombic $\delta$ phase, noticeably surrounded by the coherent $\gamma^{\prime}$ strengthening phase $(\gamma$ matrix was removed during etching).

Table II: Heat treatment conditions of 718Plus and Waspaloy used in this study.

\begin{tabular}{|c|c|c|c|}
\hline Alloy & ID & Heat treatment details $\left({ }^{\circ} \mathrm{C}\right)$ & description \\
\hline \multirow[t]{11}{*}{ 718Plus® } & "HT1 & $968^{\circ} \mathrm{C} 0.5 \mathrm{hr}, \mathrm{RAC}$ & standard heat treatment \\
\hline & & $788^{\circ} \mathrm{C} 8 \mathrm{hr}, \mathrm{FC} @ 38^{\circ} \mathrm{C} / \mathrm{hr}$ & \\
\hline & & $704^{\circ} \mathrm{C} 8 \mathrm{hr}, \mathrm{AC}$ & \\
\hline & HT2 & $\mathrm{HT} 1+732^{\circ} \mathrm{C} 1000 \mathrm{hr}, \mathrm{AC}$ & std. ht. + thermal exposure \\
\hline & HT3 & $866^{\circ} \mathrm{C} 8 \mathrm{hr}, \mathrm{AC}$ & pre-solution + std. ht. \\
\hline & & then HT1 & \\
\hline & HT4 & $866^{\circ} \mathrm{C} 8 \mathrm{hr}, \mathrm{AC}$ & pre-solution + overage + \\
\hline & & $968^{\circ} \mathrm{C} 0.5 \mathrm{hr}, \mathrm{RAC}$ & std. ht. \\
\hline & & $843^{\circ} \mathrm{C} 1 \mathrm{hr}, \mathrm{FC} @ 93^{\circ} \mathrm{C} / \mathrm{hr}$ & \\
\hline & & $788^{\circ} \mathrm{C} 8 \mathrm{hr}, \mathrm{FC} @ 38^{\circ} \mathrm{C} / \mathrm{hr}$ & \\
\hline & & $704^{\circ} \mathrm{C} 8 \mathrm{hr}, \mathrm{AC}$ & \\
\hline \multirow[t]{4}{*}{ Waspaloy } & W1 & $1018^{\circ} \mathrm{C} 1 \mathrm{hr}, \mathrm{WQ}$ & standard heat treatment \\
\hline & & $843^{\circ} \mathrm{C} 4 \mathrm{hr}, \mathrm{AC}$ & \\
\hline & & $760^{\circ} \mathrm{C} 16 \mathrm{hr}, \mathrm{AC}$ & \\
\hline & W2 & $\mathrm{W} 1+732^{\circ} \mathrm{C} 1000 \mathrm{hr}, \mathrm{AC}$ & std. ht. + thermal exposure \\
\hline
\end{tabular}

Table III: Summary of microstructural features for 718Plus and Waspaloy material conditions.

\begin{tabular}{lcccccc}
\hline \multirow{2}{*}{ Alloy } & \multirow{2}{*}{ ID } & \multicolumn{2}{c}{$\delta$ fraction } & & \multicolumn{2}{c}{$\gamma^{\prime}$ size $(\mathrm{nm})$} \\
\cline { 3 - 4 } \cline { 6 - 7 } & & $($ wt.\%) & std. dev. & & secondary & tertiary \\
\hline \hline 718Plus ${ }^{\circledR}$ & HT1 & 6.5 & \pm 1.0 & & $\mathrm{n} / \mathrm{a}$ & 27.6 \\
& HT2 & 5.9 & \pm 0.9 & & $\mathrm{n} / \mathrm{a}$ & 59.6 \\
& HT3 & 7.6 & \pm 2.9 & & $\mathrm{n} / \mathrm{a}$ & 31.4 \\
& HT4 & 11.9 & \pm 2.7 & & $\mathrm{n} / \mathrm{a}$ & 38.4 \\
\hline Waspaloy & $\mathrm{W} 1$ & $\mathrm{n} / \mathrm{a}$ & $\mathrm{n} / \mathrm{a}$ & & 144.4 & 40.5 \\
& $\mathrm{~W} 2$ & $\mathrm{n} / \mathrm{a}$ & $\mathrm{n} / \mathrm{a}$ & & 135.4 & 44.3 \\
\hline * Grain size: & 718Plus ${ }^{\circledR}, 24$ to $61 \mu \mathrm{m}$ (ASTM 5 to 7.5) \\
& Waspaloy, 20 to $24 \mu \mathrm{m}$ (ASTM 7.5 to 8.0)
\end{tabular}

For convention, intragranular $\gamma^{\prime}$ precipitates larger and smaller than $100 \mathrm{~nm}$ were classified as secondary and tertiary $\gamma^{\prime}$ respectively. There were no primary $\gamma^{\prime}$ precipitates observed along the grain boundaries in either 718Plus or Waspaloy material conditions. Higher magnification images of the fine $\gamma^{\prime}$ phase for each 718Plus condition are shown in Figure 4, revealing the uniformly distributed, near-spherical precipitate morphology. It is apparent from this figure that the effect of extensive thermal exposure on HT2 has resulted in significant precipitate coarsening, with a similar, less dramatic effect observed in HT4, as evidenced by a noticeable increase in $\gamma^{\prime}$ size due to the applied overaging sequence ( $c f$. HT1 and HT3). In comparison, Figure 4 also shows that both of the Waspaloy W1 and W2 conditions exhibit a bimodal, spherical precipitate structure with the secondary $\gamma^{\prime}$ size approximately three times larger than the tertiary. It is also apparent that the $732^{\circ} \mathrm{C}\left(1350^{\circ} \mathrm{F}\right)$ thermal exposure of $\mathrm{W} 2$ appears to have had no influence on $\gamma^{\prime}$ coarsening kinetics at this temperature. Comparing the precipitate sizes of Figure 4, it is also apparent that the tertiary $\gamma^{\prime}$ size for Waspaloy is of the same magnitude of the average $\gamma^{\prime}$ observed in 718Plus. Quantitative microstructural details for each material condition have been summarized in Table III. 


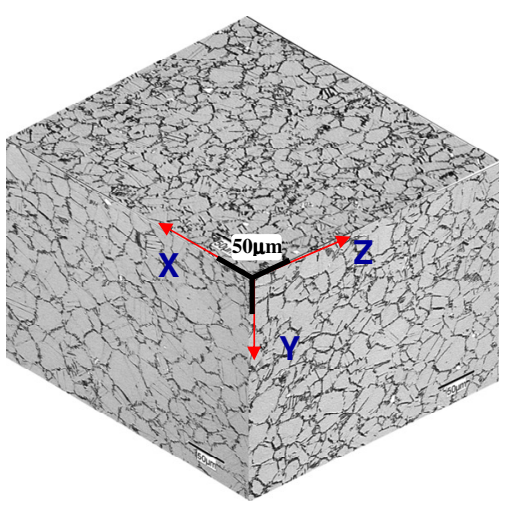

HT1

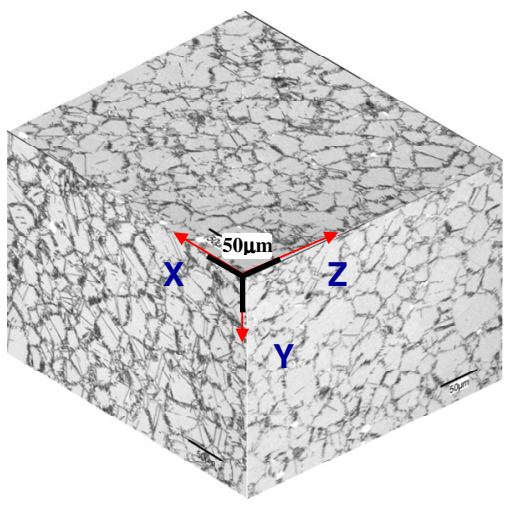

HT4

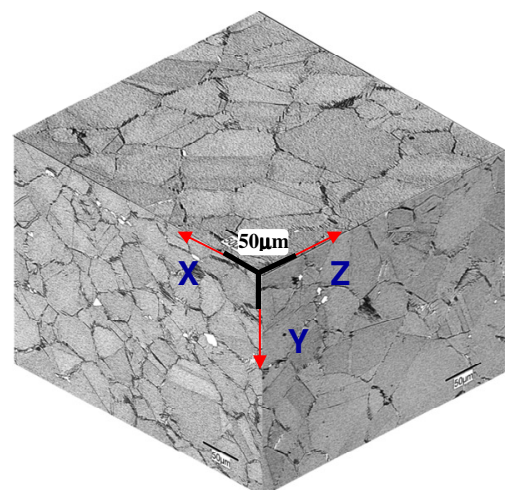

HT2

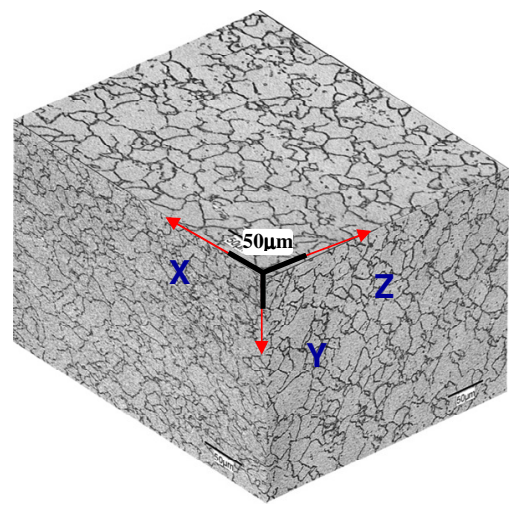

W1

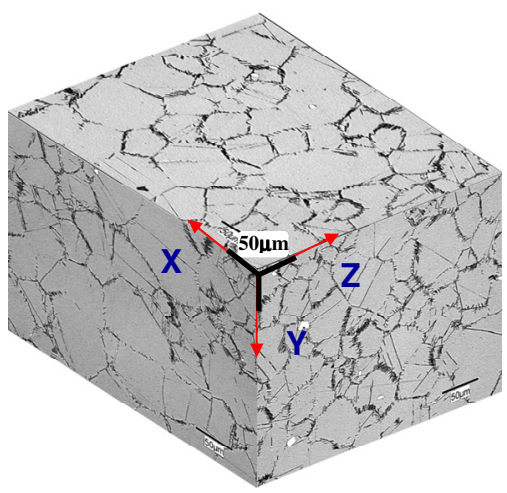

HT3

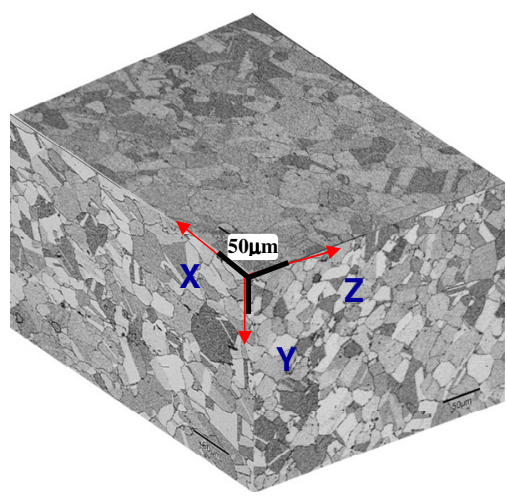

W2

Figure 1: Equiaxed grain structure of both 718Plus (HT1-HT4) and Waspaloy (W1-W2) billet materials (note: Random samples taken from various mid-radius billet locations).
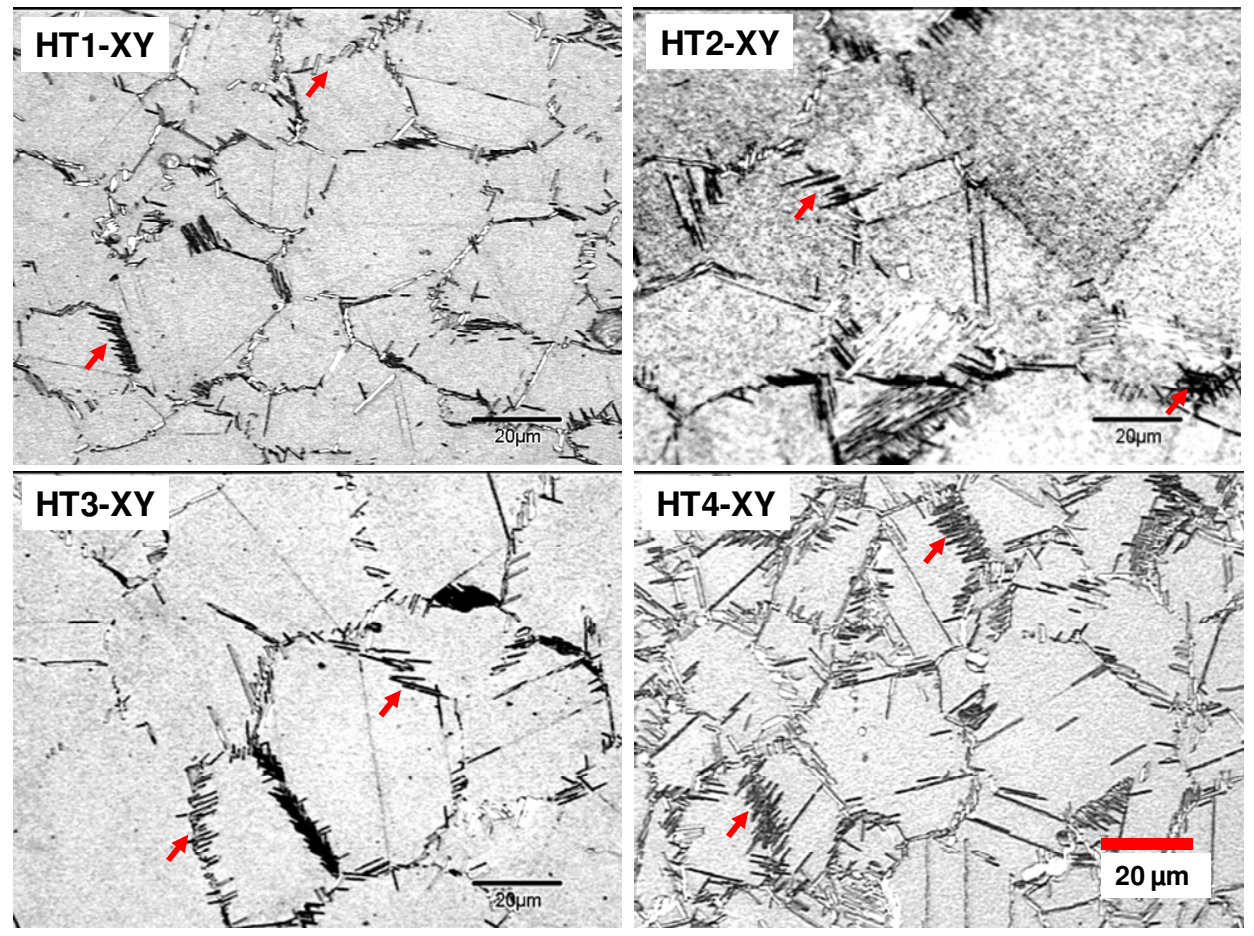

Figure 2: Location of $\delta$ phase precipitates primarily at grain boundaries for 718Plus. 


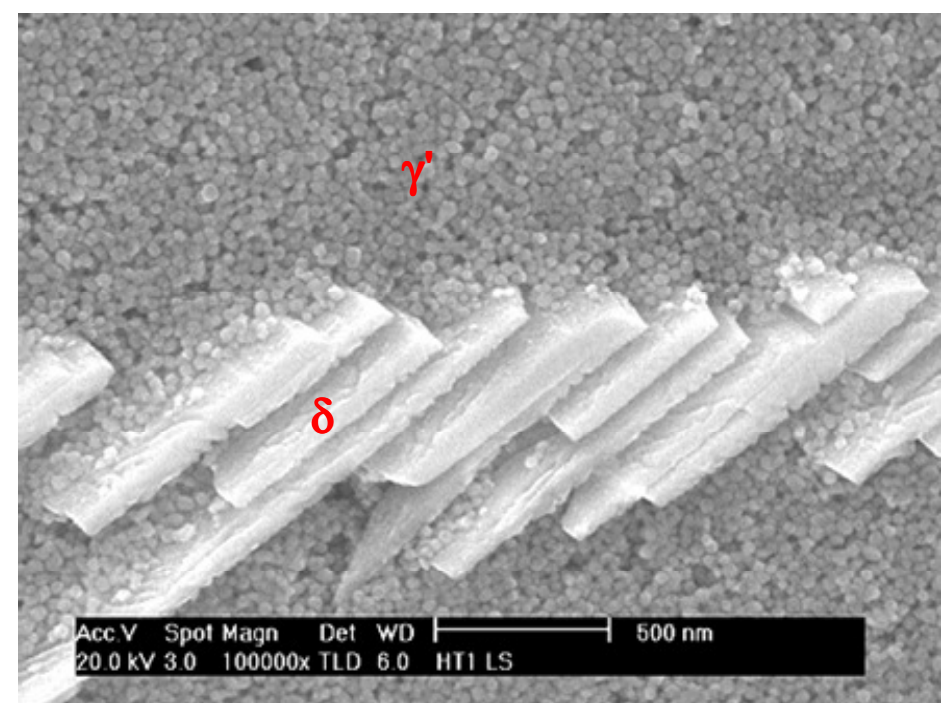

Figure 3: Typical rod-shaped $\delta$ precipitate structure surrounded by fine $\gamma^{\prime}$ phase observed in all 718Plus HT1-HT4 material conditions ( $\gamma$ matrix was removed during etching).

\section{Test Methods}

The effects of temperature (i.e. $649^{\circ} \mathrm{C}\left(1200^{\circ} \mathrm{F}\right)$ and $704^{\circ} \mathrm{C}\left(1300^{\circ} \mathrm{F}\right)$ and hold-time (i.e. 0 s and 100 s) on fatigue crack nucleation and propagation behaviour were characterized using smooth cylindrical fatigue specimens and compact tension $\mathrm{C}(\mathrm{T})$ crack growth rate specimens, respectively. A summary of the overall test matrix used in this study is shown in Table IV. The following is a brief description of the experimental test procedures used for mechanical testing.

Table IV: Overall test matrix for fatigue and dwell-fatigue characterization testing.

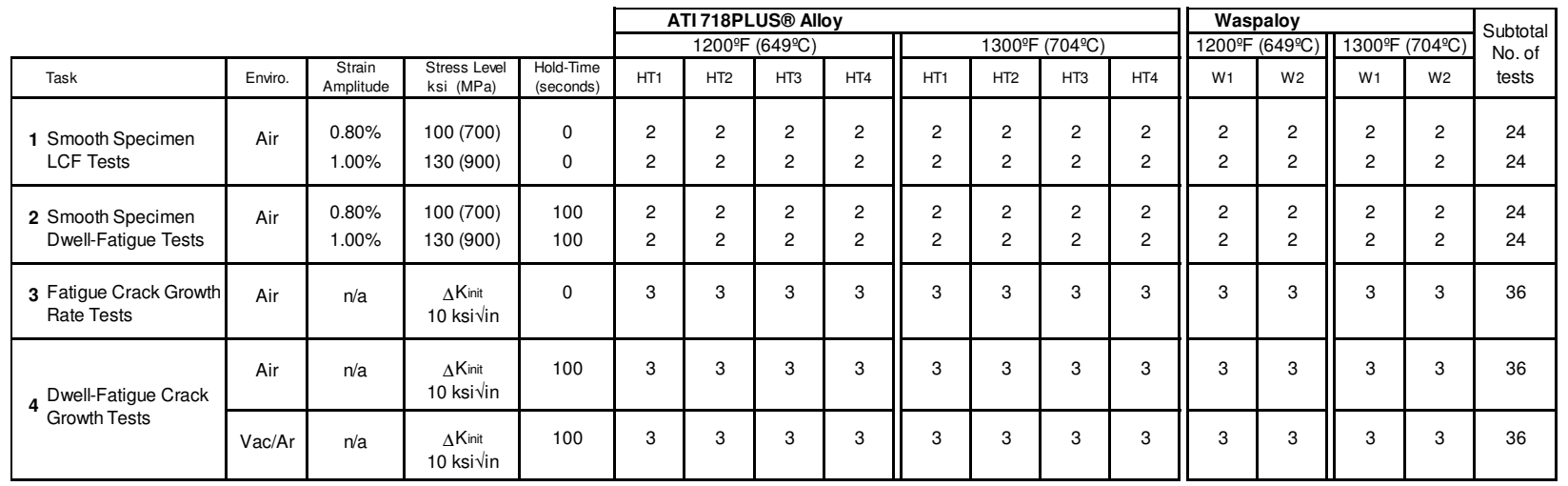

\section{Smooth Cylindrical Specimen Testing}

ASTM E606 strain-controlled fatigue tests were carried for each microstructural condition using a standard smooth-cylindrical specimen geometry with a $6.35 \mathrm{~mm}(0.25 \mathrm{in})$ gage diameter and $20.3 \mathrm{~mm}$ (0.80 in) gage length prepared using a low stress grind and fine longitudinal polishing [iv]. Two total strain ranges (TSR), $0.8 \%$ and $1.0 \%$, were used in the axial fatigue tests, translating to an initial pseudo-stress amplitude levels of $700 \mathrm{MPa}(100 \mathrm{ksi})$ and $900 \mathrm{MPa}(130$ ksi) respectively. The tests were carried out using a triangular waveform and a strain ratio of $\mathrm{R}_{\varepsilon}=$ 0 . A test frequency of $0.33 \mathrm{~Hz}$ was used for determination of standard LCF life and for determination of the effects of creep-fatigue and/or environmental interaction; a 100 second hold-time at maximum stress during cyclic loading was implemented, resulting in an effective test frequency of $0.0097 \mathrm{~Hz}$. Initial and half-life stress-strain behaviour (i.e. elastic and plastic 
damage accumulation), as well as the initiation $\left(\mathrm{N}_{\mathrm{i}}\right)$ and fatigue life $\left(\mathrm{N}_{\mathrm{f}}\right)$ were reported for both 100s dwell and no-dwell tests. Initiation life was characterized during testing as the number of cycles required, after stabilization, to reach a $30 \%$ load drop in peak maximum stress.
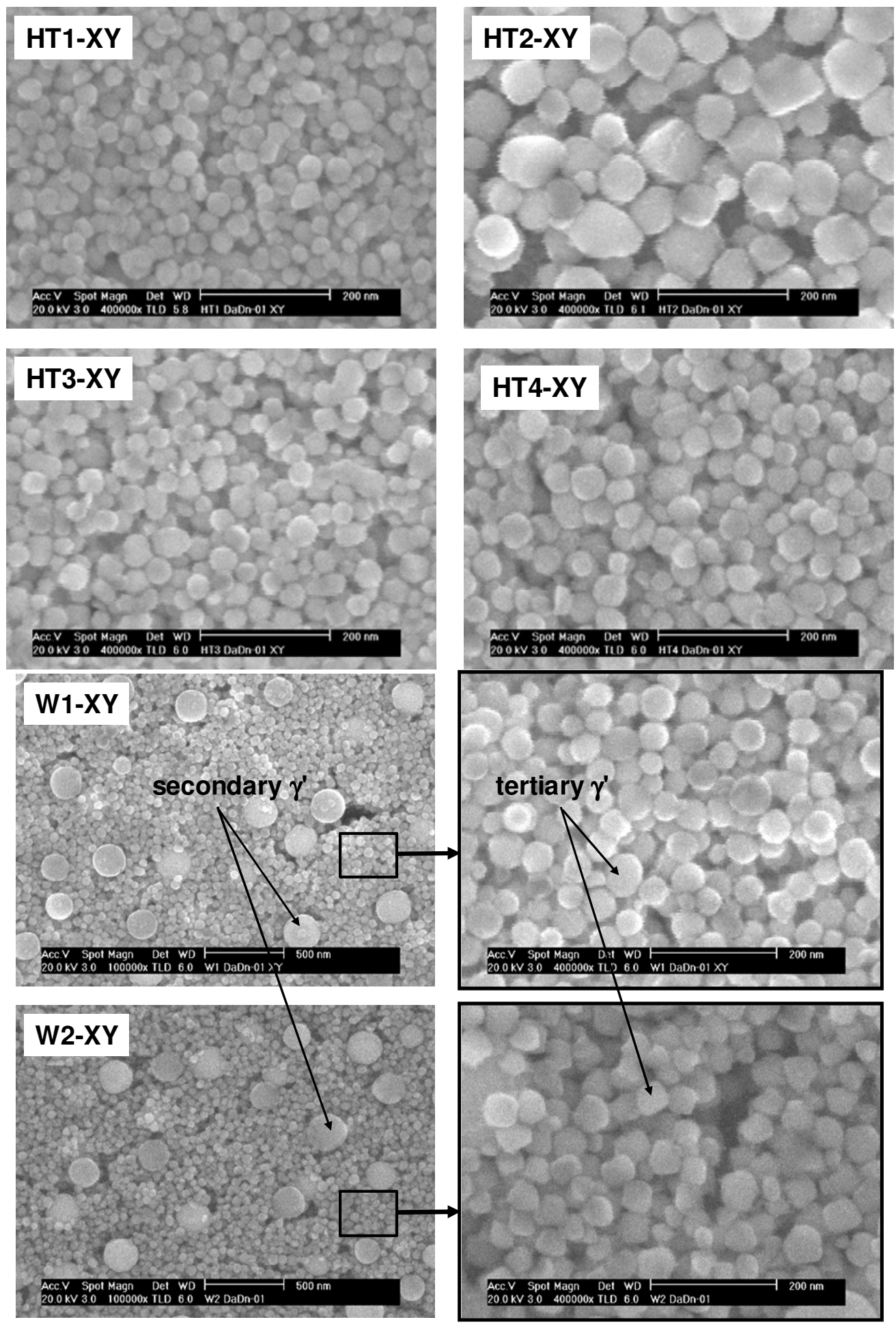

Figure 4: Spherical $\gamma^{\prime}$ morphology observed in 718Plus HT1-HT4 conditions and bimodal $\gamma^{\prime}$ distribution observed in Waspaloy W1 and W2 material conditions. 


\section{Compact Tension Specimen Testing}

The FCGR and Dwell FCGR behaviour was determined for each material condition using the ASTM E647 test method and a standard C(T) specimen geometry [v]. Tests were conducted at a stress ratio level of $\mathrm{R}=0.1$ and direct-current potential difference (DCPD) crack monitoring instrumentation was used to monitor the crack growth rate in-situ as a function of stress intensity. A test frequency of $10 \mathrm{~Hz}$ and a sinusoidal waveform were used for FCGR tests, whereas the Dwell FCGR tests utilized a trapezoidal waveform and had an effective cyclic frequency of $0.0097 \mathrm{~Hz}$ due to the $100 \mathrm{~s}$ dwell period imposed at peak stress during cyclic loading. Waveform generation, crack growth rate $(\mathrm{da} / \mathrm{dN})$ calculations and stress intensity range $(\Delta \mathrm{K})$ calculations were performed in real-time utilizing FTA ${ }^{1}$ Automated Fatigue Crack Growth Testing systems. Each FCGR test consisted of three phases, namely; 1) a room-temperature fatigue precracking segment, 2) K-decreasing, (i.e. load shedding) segment, and 3) a K-increasing, (i.e. constant load-controlled) segment. Dwell FCGR tests were conducted in a similar manner; however, the K-decreasing segment was omitted due impractical time requirements when cycling at $0.0097 \mathrm{~Hz}$ at slow near-threshold crack growth rates. Post-test visual corrections and data analysis were performed for each test using the dedicated FTA software package and optical 2-axis microscope measurements.

Stereoscopic and SEM fractographic analyses were carried out on both specimen types to investigate crack nucleation and dominant fracture modes for each material and test condition.

\section{Results and Discussion}

Low Cycle Fatigue Behaviour

Overall, the LCF test results summarized in Figure 5 demonstrate that all four microstructural conditions of 718Plus have superior life compared to Waspaloy at both test temperatures, with and without 100s dwell, at both intermediate and high total strain ranges. This is an important design feature with respect to gas turbine component lifing methodologies. Several generalized observations can be made based on the results:

1. The effect of thermal exposure on Waspaloy (W2) is far more deleterious on LCF life than for 718Plus (HT2). For all test conditions investigated, W2 ranked the worst by a large margin, whereas HT2 performed comparably with the other 718Plus material conditions, and in fact, was ranked the highest with respect to LCF life under dwell conditions for both test temperatures investigated.

2. The effect of modifying the grain boundary $\delta$ precipitate phase by applying a pre-solution heat treatment (HT3) does not significantly affect the alloy's resistance to LCF and dwell-fatigue crack nucleation. In all test conditions, HT3 performed similarly to the standard HT1 heat treatment condition.

3. The presence of excessive $\delta$ phase fraction ( $7.6 \mathrm{wt} . \%$ and $11.9 \mathrm{wt} . \%$ ) does not appear to influence the LCF life under 100s dwell and no-dwell conditions.

4. For the inherent grain size variation of the materials investigated (i.e. $20 \mu \mathrm{m}$ to $60 \mu \mathrm{m}$ ), there does not appear to be a direct or independent correlation with respect to LCF life.

\footnotetext{
${ }^{1}$ Fracture Technology Associates, Bethlehem, PA
} 


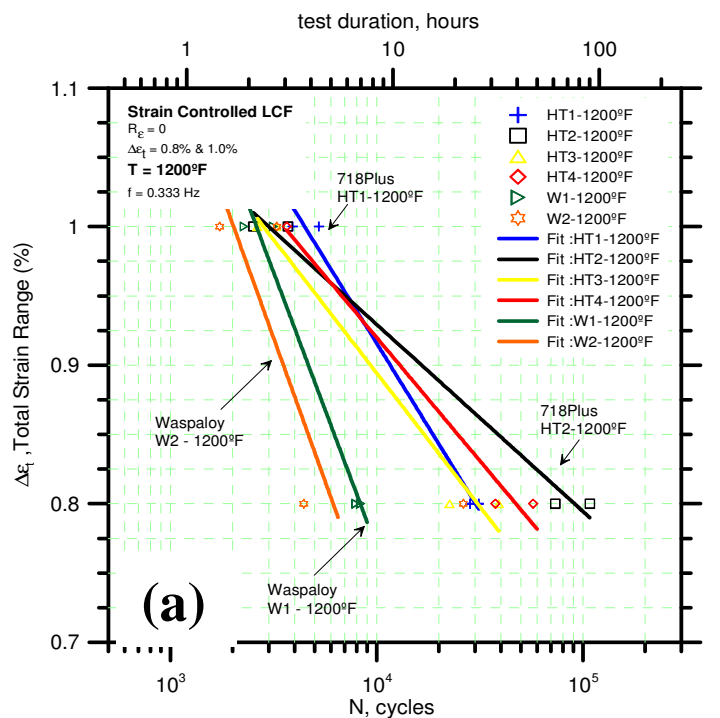

LCF: $1200^{\circ} \mathrm{F}(100 \mathrm{~s}$ dwell)

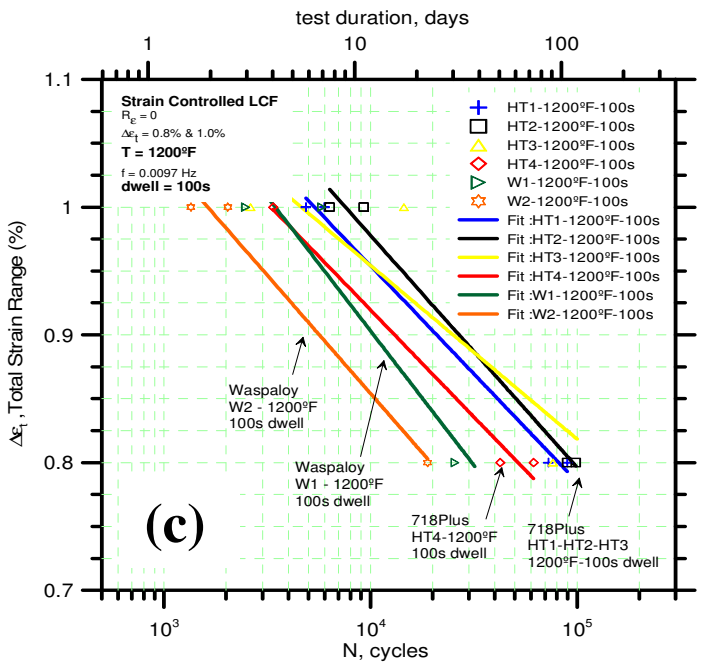

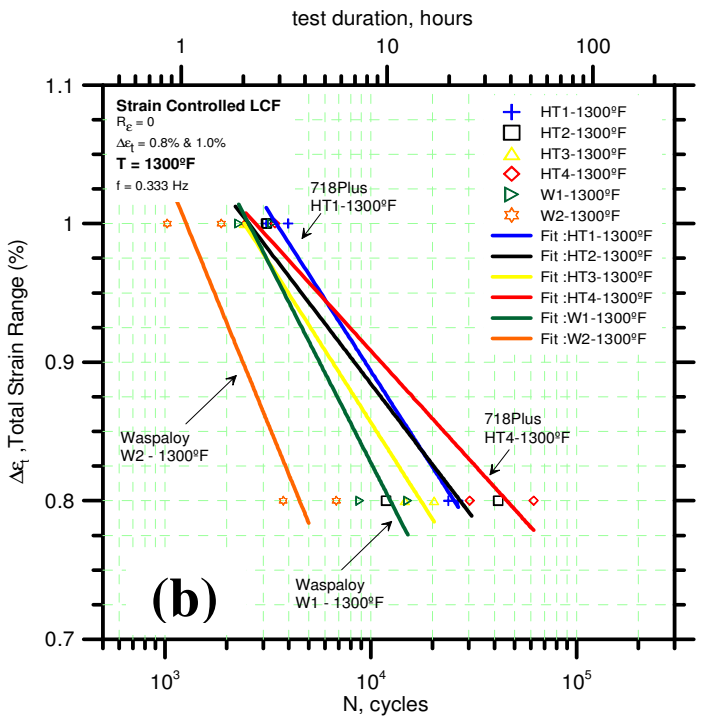

LCF: $1300^{\circ} \mathrm{F}(100$ s dwell)

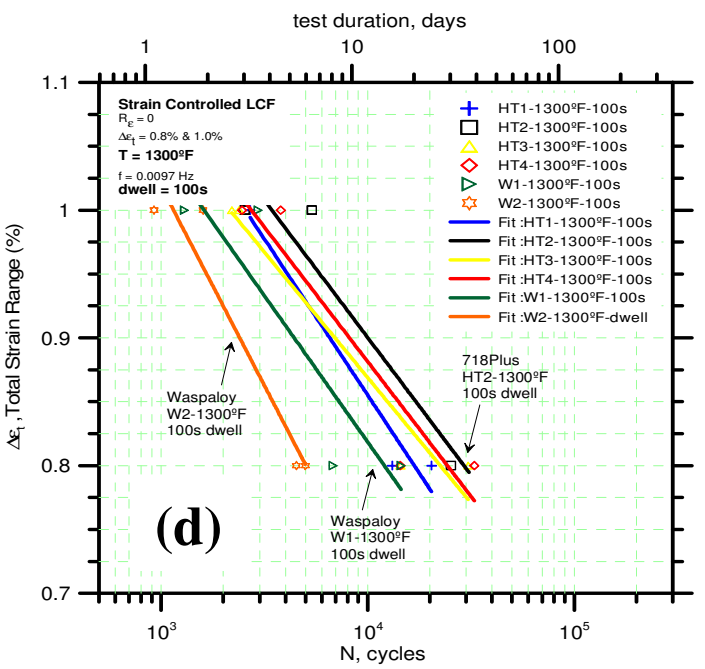

Figure 5: LCF initiation life results for $649^{\circ} \mathrm{C}\left(1200^{\circ} \mathrm{F}\right)$ and $704^{\circ} \mathrm{C}\left(1300^{\circ} \mathrm{F}\right)$ with 0 s dwell (a) and (b) and for 100s dwell test conditions (c) and (d) respectively.

One interesting observation from the results is that the effect of 100 s dwell appears to improve the crack initiation resistance of 718 Plus for those tests conducted at $649^{\circ} \mathrm{C}\left(1200^{\circ} \mathrm{F}\right)$ at both $0.8 \%$ and $1.0 \%$ total strain ranges. This is most likely due to stress relaxation during the $100 \mathrm{~s}$ dwell segments where at the lower temperatures, the creep damage mechanism is not the dominant life limiting factor under the imposed strain ranges, as shown in the example provided in Figure 6(a). However, at $704^{\circ} \mathrm{C}\left(1300^{\circ} \mathrm{F}\right)$ the opposite effect is observed, as seen in Figure 6(b) where the dwell component is detrimental and results in earlier crack formation for all material conditions investigated. This indicates that creep-fatigue interaction and possibly environmental damage mechanisms may be active with the creep damage component resulting in fatigue crack nucleation and propagation at this higher temperature for the total strain ranges investigated. 

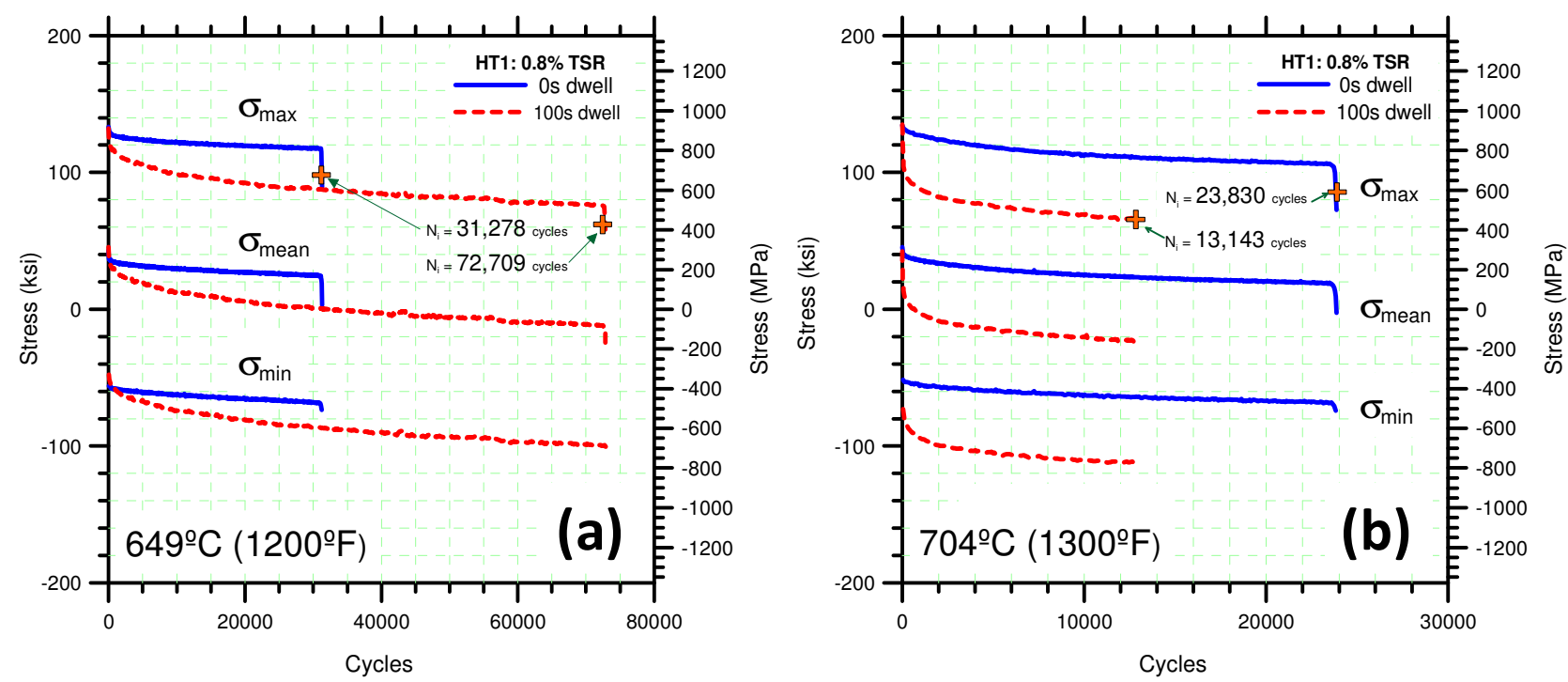

Figure 6: Cyclic stress response of HT1 tested at $0.8 \%$ TSR under 100s dwell and no-dwell conditions at (a) $649^{\circ} \mathrm{C}\left(1200^{\circ} \mathrm{F}\right)$ and (b) $704^{\circ} \mathrm{C}\left(1300^{\circ} \mathrm{F}\right)$.

Upon further inspection of Figure 6(a), it is apparent that the $100 \mathrm{~s}$ dwell effect at $649^{\circ} \mathrm{C}$ results in a decrease in the effective mean stress to a near zero condition, compared to the effective mean stress observed for the $0 \mathrm{~s}$ dwell test results. This decrease in tensile mean stress due to relaxation during inelastic damage accumulation may play a large role in the extension of LCF life due to dwell at $649^{\circ} \mathrm{C}\left(1200^{\circ} \mathrm{F}\right)$. It can also be assumed that the combined stress-oxidation effect is not as prominent at this lower temperature. At the higher test temperature, Figure 6(b), where the negative effect of 100s dwell is experienced, there is a noticeably greater decrease in maximum and minimum stresses even though there is no change in the total observed stress range. This results in an even lower overall mean stress for both dwell and non-dwell test conditions, and in fact, the 100s dwell has an effective compressive mean stress shortly after stabilization. The influence of a compressive mean stress should logically result in LCF life extension; however, it is clear from the observed trend that mean stress effect does not play a major life limiting role under dwell loading conditions at the TSR levels and temperatures investigated. In reported cases where compressive stresses are damaging to the LCF life, the material usually possesses an intrinsic cyclic hardening behaviour; which is not the case for the 718Plus material in the present study as all test conditions displayed cyclic stability to minor cyclic softening [vi]. The most probable explanation for the dwell sensitivity observed at $704^{\circ} \mathrm{C}\left(1300^{\circ} \mathrm{F}\right)$ is that the higher temperature may be providing sufficient energy to promote accelerated stress-assisted grain boundary oxidation and other temperature-time dependent damage mechanisms, which have been shown to strongly influence dwell cracking in Ni-base superalloys [vii,viii]. Additional environment controlled tests are required to elucidate these potential effects.

In general, the fractographic inspection results for all 718Plus and Waspaloy specimens demonstrated crack nucleation at or near the specimen surface in a transgranular manner perpendicular to the loading direction. There was no evidence of subsurface crack nucleation or creep cavitation for any of the tests or material conditions investigated. As expected, multiple crack nucleation sites occurred more frequently at 1\% TSR than at the $0.8 \%$ applied strain range. For all tests conducted without dwell, subsequent crack growth was predominantly transgranular, mixed with secondary cracking and cleavage fracture. It was observed that for those tests conducted with 100 s dwell, the amount of intergranular fracture increases, particularly at $704^{\circ} \mathrm{C}$ $\left(1300^{\circ} \mathrm{F}\right)$ where the dwell effect is deleterious to LCF life. 
FCGR and Dwell FCGR Results

The FCGR and Dwell FCGR test results obtained at $649^{\circ} \mathrm{C}\left(1200^{\circ} \mathrm{F}\right)$ and $704^{\circ} \mathrm{C}\left(1300^{\circ} \mathrm{F}\right)$ are shown in Figure 7(a) and (b), respectively. The mean results pertaining to the Paris' regime and fatigue crack growth threshold are given in Table $\mathrm{V}$. The $\Delta \mathrm{K}_{\mathrm{TH}}$ values were calculated by fitting a straight line through the last decade of data and calculating the corresponding $\Delta \mathrm{K}$ for a crack growth rate of $1.0 \times 10^{-10} \mathrm{~m} /$ cycle $\left(4 \times 10^{-9} \mathrm{in} /\right.$ cycle $)$.

Table V: Averaged Paris' regime equation parameters and threshold stress intensity values.

\begin{tabular}{|c|c|c|c|c|c|c|}
\hline \multirow{2}{*}{ Alloy } & \multirow{2}{*}{ ID } & \multirow{2}{*}{ Temp. $\left({ }^{\circ} \mathrm{C}\right)$} & \multirow{2}{*}{ Dwell (s) } & \multicolumn{2}{|c|}{$\mathrm{da} / \mathrm{dN}=\mathrm{C} * \Delta \mathrm{K}^{\mathrm{B}}$} & \multirow{2}{*}{$\Delta \mathrm{K}_{\mathrm{TH}}\left(\mathrm{ksi-in}{ }^{1 / 2}\right)$} \\
\hline & & & & Slope (B) & Intercept $(\mathrm{C})$ & \\
\hline \multirow[t]{16}{*}{718 Plus® } & HT1 & 649 & 0 & 2.470 & $3.239 \mathrm{E}-09$ & 9.45 \\
\hline & HT1 & 649 & 100 & 2.371 & $1.8731 \mathrm{E}-06$ & \\
\hline & HT1 & 704 & 0 & 2.098 & $1.495 \mathrm{E}-08$ & 10.20 \\
\hline & HT1 & 704 & 100 & 3.977 & $7.871 \mathrm{E}-08$ & \\
\hline & $\overline{\mathrm{HT}} 2$ & 649 & 0 & 2.775 & $1.386 \mathrm{E}-09$ & 8.05 \\
\hline & HT2 & 649 & 100 & 5.740 & $7.068 \mathrm{E}-10$ & \\
\hline & HT2 & 704 & 0 & 2.456 & $5.157 \mathrm{E}-09$ & 9.15 \\
\hline & HT2 & 704 & 100 & 5.092 & $1.096 \mathrm{E}-10$ & \\
\hline & $\overline{\text { HT3 }}$ & 649 & 0 & 2.481 & $2.582 \mathrm{E}-09$ & 9.43 \\
\hline & HT3 & 649 & 100 & 3.660 & $6.163 \mathrm{E}-08$ & \\
\hline & HT3 & 704 & 0 & 2.319 & $7.788 \mathrm{E}-09$ & 10.36 \\
\hline & HT3 & 704 & 100 & 4.056 & $9.171 \mathrm{E}-08$ & \\
\hline & $\begin{array}{l}\text { HT4 } \\
\end{array}$ & 649 & 0 & 2.431 & $3.217 \mathrm{E}-09$ & 8.54 \\
\hline & HT4 & 649 & 100 & 3.069 & $2.118 \mathrm{E}-07$ & \\
\hline & HT4 & 704 & 0 & 2.263 & $8.106 \mathrm{E}-09$ & 10.53 \\
\hline & HT4 & 704 & 100 & 3.873 & $9.455 \mathrm{E}-07$ & \\
\hline \multirow[t]{8}{*}{ Waspaloy } & W1 & 649 & 0 & 2.147 & $9.937 \mathrm{E}-09$ & 5.55 \\
\hline & W1 & 649 & 100 & 3.619 & $8.578 \mathrm{E}-10$ & \\
\hline & W1 & 704 & 0 & 2.133 & $1.247 \mathrm{E}-08$ & 6.01 \\
\hline & W1 & 704 & 100 & 3.271 & $4.782 \mathrm{E}-08$ & \\
\hline & W2 & 649 & 0 & 2.420 & $4.225 \mathrm{E}-09$ & 6.88 \\
\hline & W2 & 649 & 100 & 2.752 & $3.956 \mathrm{E}-09$ & \\
\hline & W2 & 704 & 0 & 2.342 & $7.008 \mathrm{E}-09$ & 6.97 \\
\hline & W2 & 704 & 100 & 3.234 & $1.776 \mathrm{E}-09$ & \\
\hline
\end{tabular}

\section{FCGR Results}

As can be seen from Figure 7 and Table V, the crack growth rate in the Paris' regime was nearly identical for all six alloys under non-dwell conditions. It wasn't until the $\Delta \mathrm{K}$ levels approached near-threshold values that differences began to emerge. At $649^{\circ} \mathrm{C}\left(1200^{\circ} \mathrm{F}\right), \mathrm{HT} 1$ and $\mathrm{HT} 3 \mathrm{had}$ nearly identical $\Delta \mathrm{K}_{\mathrm{TH}}$ values of approximately $10.4 \mathrm{MPa}-\mathrm{m}^{1 / 2}\left(9.5 \mathrm{ksi}^{-\mathrm{in}^{1 / 2}}\right)$, which were the highest among the six materials tested. HT2 and HT4 had $\Delta \mathrm{K}_{\mathrm{TH}}$ values of $8.8 \mathrm{MPa}-\mathrm{m}^{1 / 2}(8.0 \mathrm{ksi}-$ in $\left.^{1 / 2}\right)$ and $9.4 \mathrm{MPa}-\mathrm{m}^{1 / 2}\left(8.5 \mathrm{ksi}^{-i n^{1 / 2}}\right)$, respectively. W1 and $\mathrm{W} 2$ had the lowest threshold of all the alloys, which were $6.1 \mathrm{MPa}^{1 / 2}\left(5.6 \mathrm{ksi}^{1 / \mathrm{in}^{1 / 2}}\right)$ and $7.5 \mathrm{MPa}^{1 / 2}\left(6.9 \mathrm{ksi}^{1 / \mathrm{in}^{1 / 2}}\right)$, correspondingly. It should be noted that for Waspaloy, the $\Delta \mathrm{K}_{\mathrm{TH}}$ value increased as a result of thermal exposure where as for the 718Plus material, the $\Delta \mathrm{K}_{\mathrm{TH}}$ value decreased. FCGR data recorded from a single vacuum test performed at $649^{\circ} \mathrm{C}$ on $\mathrm{HT} 1$ is also included in Figure 7 (a) for comparison. It can be seen from this figure that under vacuum non-dwell test conditions, the FCGR behaviour in the Paris' regime was nearly identical to all of the other material conditions and like the others; its behaviour becomes unique only in the lower, near-threshold regions of the curve.

The FCGR data at $704^{\circ} \mathrm{C}\left(1300^{\circ} \mathrm{F}\right)$ showed the exact same trends as the data at $649^{\circ} \mathrm{C}\left(1200^{\circ} \mathrm{F}\right)$, with the threshold values for each material condition increasing slightly. The $\Delta \mathrm{K}_{\mathrm{TH}}$ values for

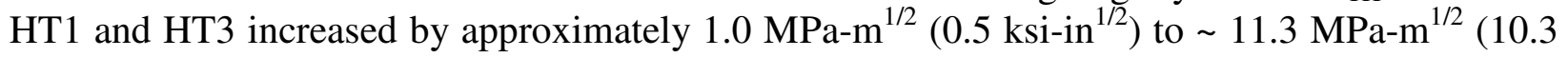


$\left.\mathrm{ksi}^{1 / 2}{ }^{1 / 2}\right)$. The $\Delta \mathrm{K}_{\mathrm{TH}}$ value of HT2 and HT4 both increased to $10.1 \mathrm{MPa}^{\mathrm{m}} \mathrm{m}^{1 / 2}\left(9.2 \mathrm{ksi}-\mathrm{in}^{1 / 2}\right)$ and 11.6 $\mathrm{MPa}^{\mathrm{m}} \mathrm{m}^{1 / 2}\left(10.5 \mathrm{ksi}-\mathrm{in}^{1 / 2}\right)$, respectively. The $\Delta \mathrm{K}_{\mathrm{TH}}$ for $\mathrm{W} 1$ and $\mathrm{W} 2$ also increased, albeit at a reduced rate compared to the 718 Plus alloy conditions, to $6.6 \mathrm{MPa}-\mathrm{m}^{1 / 2}\left(6.0 \mathrm{ksi}-\mathrm{in}^{1 / 2}\right)$ and 7.7 $\mathrm{MPa}-\mathrm{m}^{1 / 2}\left(7.0 \mathrm{ksi}-\mathrm{in}^{1 / 2}\right)$, in that order.

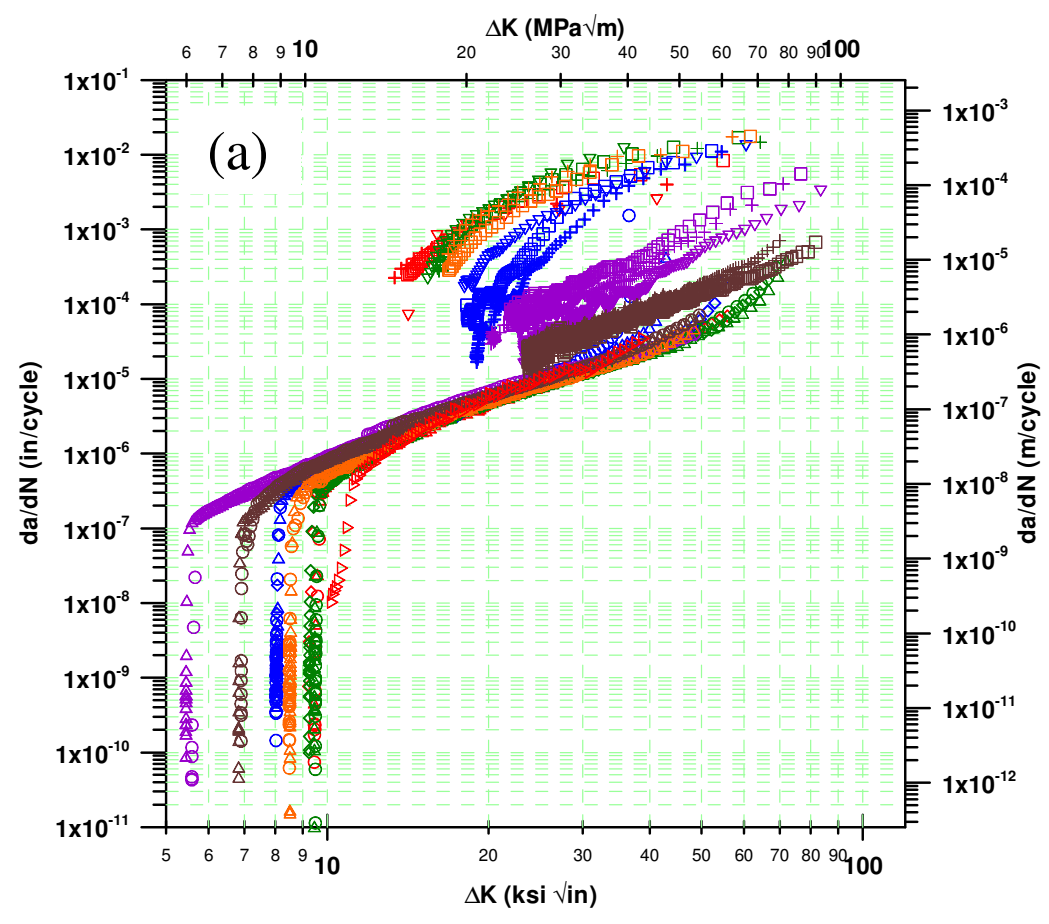

\begin{tabular}{|c|c|}
\hline & $\begin{array}{l}(\mathbf{R}=+\mathbf{0 . 1 0}, \mathbf{T}=\mathbf{1 2 0 0} \text { oF }) \\
\text { HT1-DaDn-01 }(\mathrm{f}=10 \mathrm{~Hz})\end{array}$ \\
\hline$\triangle$ & HT1-DaDn-02 ( $f=10 \mathrm{~Hz})$ \\
\hline$\diamond$ & HT1-DaDn-03 $(f=10 \mathrm{~Hz})$ \\
\hline$\triangleright$ & HT1-DaDn-19 $(f=10 \mathrm{~Hz}$, Vacuum \\
\hline$\square$ & HT1-DaDn-04 (100 sec dwell) \\
\hline+ & HT1-DaDn-05 (100 sec dwell) \\
\hline$\nabla$ & HT1-DaDn-06 (100 sec dwell) \\
\hline$\bigcirc$ & HT2-DaDn-01 $(f=10 \mathrm{~Hz})$ \\
\hline$\triangle$ & HT2-DaDn-02 $(f=10 \mathrm{~Hz})$ \\
\hline$\diamond$ & HT2-DaDn-03 $(f=10 \mathrm{~Hz})$ \\
\hline$\square$ & HT2-DaDn-04 (100 sec dwell) \\
\hline+ & HT2-DaDn-05 (100 sec dwell) \\
\hline$\nabla$ & HT2-DaDn-06 (100 sec dwell) \\
\hline O & HT3-DaDn-01 $(f=10 \mathrm{~Hz})$ \\
\hline$\triangle$ & HT3-DaDn-02 $(f=10 \mathrm{~Hz})$ \\
\hline$\diamond$ & HT3-DaDn-03 $(f=10 \mathrm{~Hz})$ \\
\hline - & HT3-DaDn-04 (100 sec dwell) \\
\hline 4 & HT3-DaDn-05 (100 sec dwell) \\
\hline$\nabla$ & HT3-DaDn-06 (100 sec dwell) \\
\hline 0 & HT4-DaDn-01 $(f=10 \mathrm{~Hz})$ \\
\hline$\triangle$ & HT4-DaDn-03 $(f=10 \mathrm{~Hz})$ \\
\hline$\square$ & HT4-DaDn-04 (100 sec dwell) \\
\hline+ & HT4-DaDn-05 (100 sec dwell) \\
\hline$\nabla$ & HT4-DaDn-06 (100 sec dwell) \\
\hline O & W1-DaDn-01 $(f=10 \mathrm{~Hz})$ \\
\hline$\triangle$ & W1-DaDn-03 $(f=10 \mathrm{~Hz})$ \\
\hline 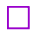 & W1-DaDn-04 (100 sec dwell) \\
\hline † & W1-DaDn-05 (100 sec dwell) \\
\hline$\nabla$ & W1-DaDn-06 (100 sec dwell) \\
\hline O & W2-DaDn-01 $(f=10 \mathrm{~Hz})$ \\
\hline$\triangle$ & W2-DaDn-02 $(f=10 \mathrm{~Hz})$ \\
\hline L & W2-DaDn-04 (100 sec dwell) \\
\hline+ & W2-DaDn-06 (100 sec dwell) \\
\hline
\end{tabular}




\section{FCGR \& CFCGR at $1300^{\circ} \mathrm{F}$}
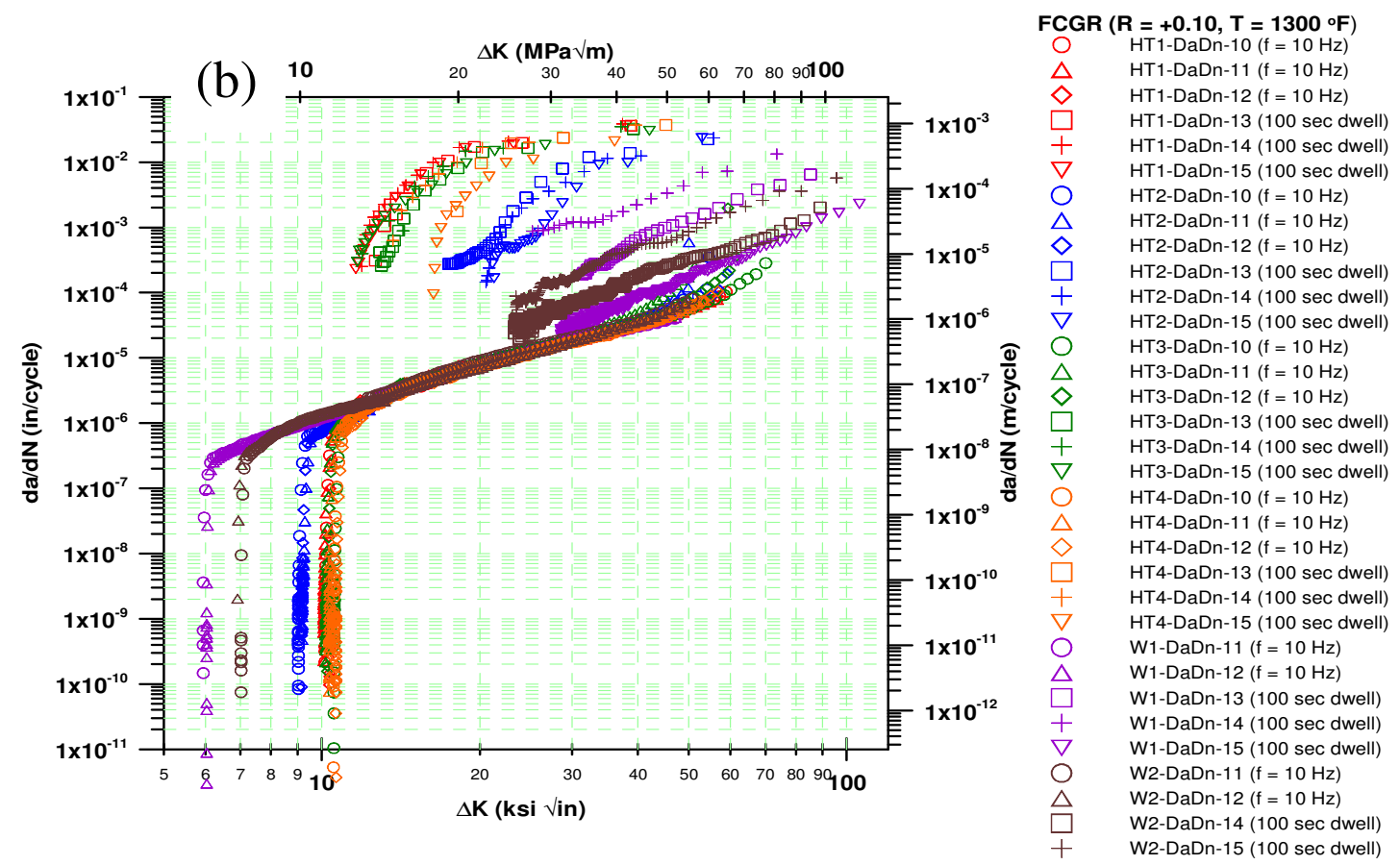

Figure 7: FCGR and Dwell FCGR test results at (a) $649^{\circ} \mathrm{C}\left(1200^{\circ} \mathrm{F}\right)$ and (b) $704^{\circ} \mathrm{C}\left(1300^{\circ} \mathrm{F}\right)$.

The vast improvement of the fatigue threshold values of HT1, HT2, and HT3 over Waspaloy at $649^{\circ} \mathrm{C}\left(1200^{\circ} \mathrm{F}\right)$ and $704^{\circ} \mathrm{C}\left(1300^{\circ} \mathrm{F}\right)$ is a significant advantage for the 718 Plus alloy from an engine design perspective. The increased $\Delta \mathrm{K}_{\mathrm{TH}}$ values indicate that $718 \mathrm{Plus}$ has a potentially higher application stress range for which cracks or defects are effectively non-propagating compared to Waspaloy. Even after prolonged heat exposure (HT2), the 718Plus alloy still maintains a significant advantage over the pristine Waspaloy (W1) or thermally exposed Waspaloy (W2) conditions, indicating favourable thermal stability of the 718Plus alloy at the test temperatures investigated. To investigate micro-mechanical behaviour, a comparison of measured grain size vs. $\Delta \mathrm{K}_{\mathrm{TH}}$ revealed no direct correlation for either 718 Plus or Waspaloy material conditions. Similarly, there seemed to be a weak association between $\delta$ phase fraction and $\Delta \mathrm{K}_{\mathrm{TH}}$ but with the relatively large standard deviations in the measured $\delta$ fraction, it would be difficult to argue that such a correlation exists. However, there does appear to be an inverse correlation between the intragranular $\gamma^{\prime}$ precipitate size and the measured $\Delta \mathrm{K}_{\mathrm{TH}}$. This correlation was confirmed by the test results as the intragranular $\gamma^{\prime}$ size rankings (from smallest to largest) was HT1/HT3, HT4, HT2, W2, and W1, which also happens to be the rankings of the $\Delta \mathrm{K}_{\mathrm{TH}}$ (from highest to lowest). Connections between other microstructural features and fatigue threshold values were evaluated and studied but no other strong relationships were found.

As mentioned previously, data collected from tests performed under vacuum on HT1 material was also presented in Figure 7(a). The steady state crack growth characteristics of the non-dwell tests performed in vacuum and in air tested were nearly identical, indicating no oxidation effect or damage at those $\Delta \mathrm{K}$ levels. Like the other non-dwell FCGR tests, its behaviour did not become unique until $\Delta \mathrm{K}$ levels approached the near-threshold regime. Initially, it appeared as though it would have the highest $\Delta \mathrm{K}_{\mathrm{TH}}$ value of all the material conditions, contravening the 
initial presumption that the FCGR data in the near-threshold regime was being heavily affected by oxide-induced crack closure. However, as the test progressed, the vacuum FCGR data began to differentiate from the FCGR tests performed in air in that it continued to decline but in a less rapid manner, until the test was stopped due to time restraints. The data recorded before the test was halted indicated that oxidation was, at the very least, a factor in the abrupt drop in fatigue crack growth rates of the specimens performed in an oxygen environment. Additional tests are in progress to elucidate the environmental effects on FCGR and Dwell FCGR behaviour.

\section{Dwell FCGR Results}

In comparison to the non-dwell FCGR results, the effect of dwell loading at peak tensile stress conditions resulted in steeper measured slopes of up to 2 times magnitude for both the 718Plus and Waspaloy material conditions, as shown in Table V. Also noteworthy, as seen in Figure 7, the Dwell FCGR test results indicated a reverse of the material ranking that was observed during the non-dwell threshold FCGR testing. In other words, those materials that exhibited higher $\Delta \mathrm{K}_{\mathrm{TH}}$ values displayed lower Dwell FCGR resistance. At $649^{\circ} \mathrm{C}$, HT1 and HT3, showing nearly identical behaviour, along with HT4 had the fastest crack growth rates once the $100 \mathrm{sec}$ dwell time was introduced, increasing by roughly two orders of magnitude at the same $\Delta \mathrm{K}$ levels. HT2 exhibited a greater resistance to dwell-fatigue crack growth than HT1, HT3, and HT4 but not as resistant as W1 and W2, which had the slowest crack growth rates under dwell fatigue conditions. The thermally exposed W2 condition showed the greatest resistance to dwell fatigue crack propagation, while W1 exhibited crack propagation behaviour slower than HT2 but faster than W2.

At $704^{\circ} \mathrm{C}$, the dwell fatigue data also followed the trends seen at the lower temperature with a slightly larger difference in dwell fatigue crack growth rates between HT1 and HT3, HT4, HT2, and W1 and W2. It should be noted however that at this higher test temperature, HT4's dwellfatigue crack propagation resistance improved relative to the other 718Plus alloys. At the lower temperature, HT4 exhibited nearly identical behaviour to HT1 and HT3, however, at the higher temperature, HT4 showed improved resistance and began approaching the dwell crack growth rates of HT2.

Compared to Waspaloy, the dwell-fatigue crack growth rate resistance of the 718Plus alloy in all four microstructural conditions did not rank as high. Again, this may be associated with the bimodal $\gamma^{\prime}$ precipitate phase of Waspaloy. In general, increasing the intragranular $\gamma^{\prime}$ fraction and size distribution will increase dwell-fatigue resistance [ix, $\mathrm{x}$ ]. This is caused by the $\gamma^{\prime}$ hardening precipitate, particularly the ultrafine intragranular $\gamma^{\prime}$, promoting stress relaxation at the crack tip during prolonged hold times at high temperatures [ix]. Promoting stress relaxation at the crack tip significantly reduces the driving force for crack growth and will result in improved crack growth resistance. Unlike the bimodal Waspaloy precipitate structure, the 718Plus alloys are strengthened by a unimodal ultrafine intragranular $\gamma^{\prime}$ phase, and as a result, should theoretically have less dwell-fatigue resistance. However, as can be seen in the results, after thermal exposure, the dwell-fatigue properties do improve to levels more comparable to Waspaloy. During thermal exposure, two significant microstructural changes occur: 1) the formation and growth of the $\delta$ phase and 2) coarsening of the ultrafine $\gamma^{\prime}$ hardening phase [xi]. It has been shown that grain boundary phases have a very minimal effect on improving dwell-fatigue resistance [ix]. Therefore, the $\delta$ phase will have minimal effect on the dwell-fatigue resistance, as can be seen by the data showing identical behaviour of HT1, HT3, and HT4, despite the $\delta$ fraction ranging from $6 \mathrm{wt} . \%$ to $12 \mathrm{wt} . \%$ in the three material conditions. Therefore, HT2's improved dwell fatigue 
crack propagation resistance may be related to the coarsening of the $\gamma^{\prime}$ hardening phase, which was observed to be double in size compared to HT1, HT3, and HT4, as seen in Table III. This structure results in crack-tip blunting due to significantly reduced creep resistance of the overaged condition of HT2, and to a lesser degree in HT4. In addition, the synergistic environmental effects are still being investigated via vacuum Dwell FCGR tests as grain boundary oxidation is suspected to be a major contributing factor to overall dwell fatigue resistance.

Post-fracture analysis was performed on all of the C(T) specimens in the SEM and after examining each fracture surface the following general observations were identified:

1. The HT1, HT3, and HT4 microstructures exhibited predominantly intergranular fracture with some evidence of transgranular cleavage at $649^{\circ} \mathrm{C}\left(1200^{\circ} \mathrm{F}\right)$ for dwell and no-dwell test conditions; at $704^{\circ} \mathrm{C}\left(1300^{\circ} \mathrm{F}\right)$ the fracture mode was observed to be very intergranular for 100s dwell and no-dwell test conditions.

2. The HT2 microstructure tested at both test temperatures with no-dwell exhibited more transgranular fracture than HT1, HT3, and HT4. Under dwell conditions at both test temperatures, the fracture mode of HT2 was observed to be arguably less intergranular.

3. The W1 and W2 fracture surfaces appeared to be predominantly transgranular at both test temperatures under no-dwell test conditions; however the mode was observed to become much more intergranular when subjected to 100 s hold times at both $649^{\circ} \mathrm{C}\left(1200^{\circ} \mathrm{F}\right)$ and $704^{\circ} \mathrm{C}\left(1300^{\circ} \mathrm{F}\right)$.

Figure 8 is a summary of the near-threshold fracture surfaces for each microstructural condition performed at both test temperatures under 100s dwell and no-dwell conditions. The general observation that can be made is that there appears to be an associated higher crack threshold with respect to an increase in the degree of intergranular fracture, as intergranular fracture produces a more torturous crack path and crack asperities. This irregular crack surface topography increases crack closure compared to the planar transgranular modes observed for Waspaloy, leading to higher $\Delta \mathrm{K}_{\mathrm{TH}}$ values. A greater degree of intergranular fracture is also observed at $704^{\circ} \mathrm{C}\left(1300^{\circ} \mathrm{F}\right)$ than at $649^{\circ} \mathrm{C}\left(1200^{\circ} \mathrm{F}\right)$, contributing to higher $\Delta \mathrm{K}_{\mathrm{TH}}$ values. 


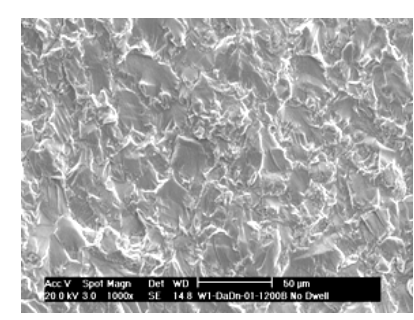

W1-1200F-nodwell

- Similar to W2

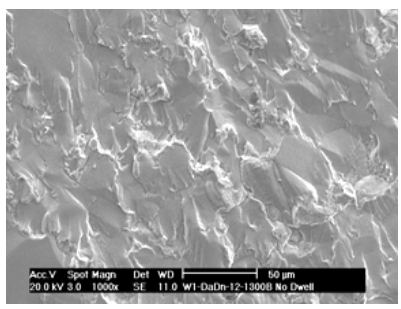

W1-1300F-nodwell

- Similar to W2

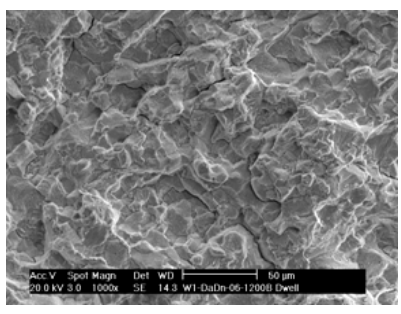

W1-1200F-100s dwell

- Similar to W2

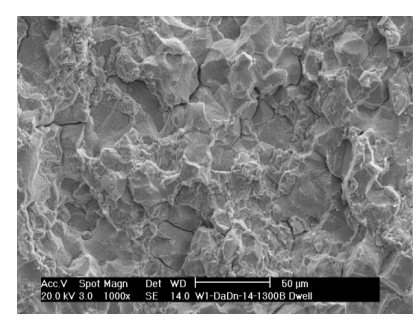

W1-1300F-100s dwell

- Similar to W2

Predominantly

transgranular

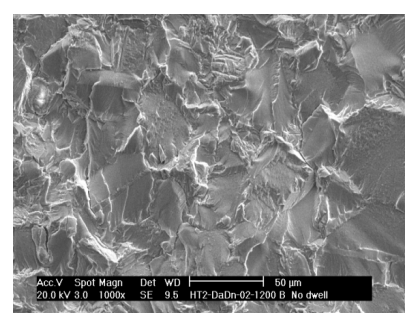

HT2-1200F-no dwell

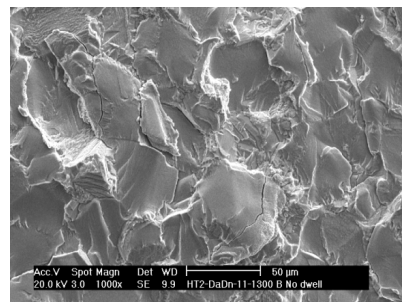

HT2-1300F-no dwell

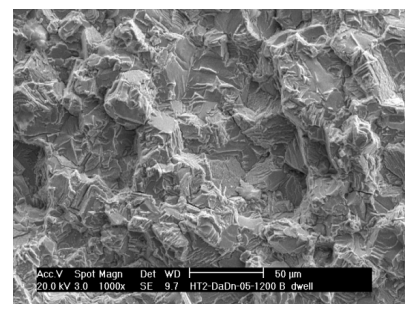

HT2-1200F-100s dwell

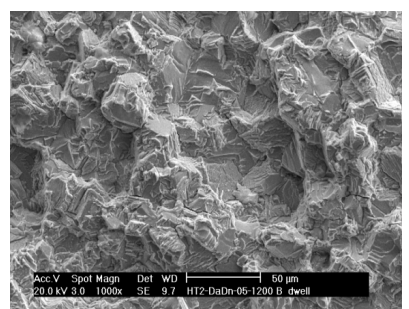

HT2-1300F-100s dwell

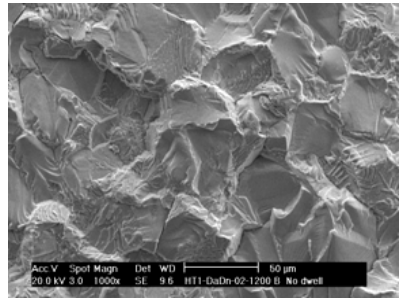

HT1-1200F-no dwell

- Similar toHT3 and HT4

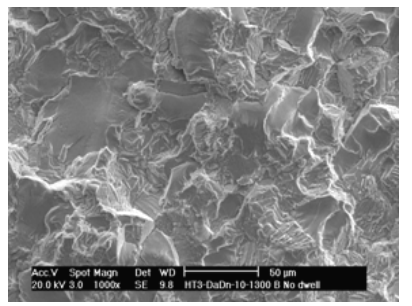

HT3-1300F-no dwell

- Similar toHT1 and HT4

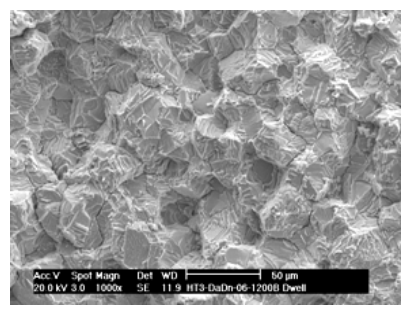

HT3-1200F-100s dwell

- Similar toHT1 and HT4

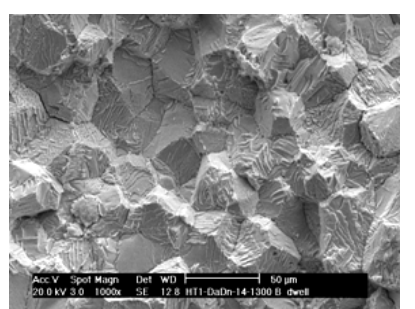

HT1-1300F-100s dwell

- Similar to HT3 and HT4

intergranular

Figure 8: Summary of FCGR and Dwell FCGR fractographic results.

\section{Conclusions}

- Overall, the LCF test results demonstrated that 718Plus has superior life compared to Waspaloy at both test temperatures, with and without 100s dwell, at both intermediate and high total strain ranges examined.

- The effect of thermal exposure on Waspaloy is far more deleterious on LCF life than for 718Plus and in fact, extensive thermal exposure of 718Plus ranked the highest with respect to LCF life under dwell conditions for both $649^{\circ} \mathrm{C}$ and $704^{\circ} \mathrm{C}$ test temperatures. 
- The effect of modifying the grain boundary $\delta$ precipitate phase by applying a pre-solution heat treatment (HT3) did not significantly affect the alloy's resistance to LCF under dwell and non-dwell conditions.

- The presence of excessive $\delta$ phase fraction does not appear to influence the LCF life under no-dwell and 100s dwell conditions.

- For the range of grain sizes investigated, there does not appear to be a direct correlation with LCF behaviour or dwell sensitivity.

- The non-dwell FCGR tests results show that the Paris' regime for all six material conditions were nearly identical.

- All four 718Plus material conditions showed a significantly higher threshold for fatigue crack propagation, particularly HT1, HT3, and HT4 which is a significant advantage over Waspaloy as it allows the 718Plus alloy to be used in higher stress applications for the temperatures investigated.

- Waspaloy demonstrated the best Dwell FCGR resistance over 718Plus; however, after thermal exposure 718Plus does improve to levels more comparable to Waspaloy, theoretically by coarsening the ultrafine $\gamma^{\prime}$ size thus decreasing creep resistance and promoting crack tip blunting.

- Post-fracture analysis showed that the primary fracture mode during FCGR testing at both temperatures was transgranular for HT2 and Waspaloy. In HT1, HT3 and HT4, the fracture mode during FCGR testing at both temperatures was predominantly intergranular at higher $\Delta \mathrm{K}$ values but shifted to a mix of intergranular and transgranular at lower $\Delta \mathrm{K}$ values.

- During Dwell FCGR testing, it was found that at $649^{\circ} \mathrm{C}$ and lower $\Delta \mathrm{K}$ values, a mix of intergranular and transgranular fracture modes were seen for all of the materials. As the $\Delta K$ increased, the fracture morphology became almost completely intergranular. At $704^{\circ} \mathrm{C}$ $\left(1300^{\circ} \mathrm{F}\right)$, the fracture mode during Dwell FCGR testing was completely intergranular at all $\Delta \mathrm{K}$ levels for each material.

- It was also generally observed from the near-threshold fracture surfaces that higher $\Delta \mathrm{K}_{\mathrm{TH}}$ appeared to associate with an increase in the degree of intergranular fracture, contributing to more crack closure and consequently higher $\Delta \mathrm{K}_{\mathrm{TH}}$ values than for Waspaloy, which exhibited a planar transgranular mode of fracture near the threshold region.

- There was a noticeable inverse correlation between the intragranular $\gamma^{\prime}$ size and the observed $\Delta \mathrm{K}_{\mathrm{TH}}$ values. Preliminary results indicate that materials with a finer tertiary $\gamma^{\prime}$ size, exhibited higher thresholds for fatigue crack propagation.

\section{References}

i. X. Liu, S. Rangararan, E. Barbero, K. Chang. W. Cao, R. Kennedy, and T. Carneiro, "Fatigue Propagation Behaviour of Newly Developed Allvac 718Plus Superalloy, Superalloys 2004, ed. K.A Green, T.M Pollock, and H. Harada, TMS, 2004, pp. 283-290.

ii. R.E. Shafrik, D.D. Ward, J.R. Groh, "Application of Alloy 718 in GE Aircraft Engines: Past, Present and Next Five Years", Superalloys 718, 625, 706 and Various Derivatives 2005, ed. E.A. Loria, TMS, 2001, pp. 1-11.

iii. R.L. Kennedy, "Allvac ${ }^{\circledR} 718$ Plus $®$, Superalloy for the Next Forty Years," Superalloys 718, 625, 706 and Various Derivatives 2005, ed. E.A. Loria, TMS, 2005, pp. 1-14. 
iv. "Standard Practice for Strain-Controlled Fatigue Testing", American Society for Testing and Materials (ASTM) E606-04.

v. "Standard Test Method for Measuring Fatigue Crack Growth Rates," American Society for Testing and Materials (ASTM) E647-05.

vi. T. Goswami and H. Haninen, "Dwell Effects on High Temperature Fatigue Damage Mechanism-Part II", Materials and Design, 22 (2001), pp. 217-236.

vii. M. Gao, S. Chen, G. Chen, and R.P. Wei, "Environmentally Enhanced Crack Growth in Nickel-based Alloys at Elevated Temperatures", Elevated Temperature Effects on Fatigue and Fracture, ASTM STP 1297, American Society for Testing and Materials, West Conshohocken, USA, 1997, pp. 74-84.

viii. R.W. Hayes, "Oxygen Embrittlement and Time-Dependent Grain-Boundary Cracking of ALLVAC 718PLUS”, Met. Trans. A., Vol. 39A, Nov 2008, pp.2596-2606.

ix. R. Mitchell, J. Lemsky, R. Ramanathan, H. Li, K. Perkins, and L. Connor, "Process Development and Microstructure and Mechanical Property Evaluation of a Dual Microstructure Heat Treated Advanced Nickel Disc Alloy," Superalloys 2008, ed. R. Reed, K. Green, P. Caron, T. Gabb, M. Fahrmann, E. Huron, S. Woodward, TMS, 2008, pp. 347-356.

x. J. Telesman, T. Gabb, A. Garg, P. Bonacuse, R Gayda, "Effect of Microstructure on Time Dependent Fatigue Crack Growth Behavior in a P/M Turbine Disc Alloy," Superalloys 2008, ed. R. Reed, K. Green, P. Caron, T. Gabb, M. Fahrmann, E. Huron, S. Woodward, TMS, 2008, pp. 807-816.

xi . W. Cao, "Thermal Stability Characterization of Ni-Base ATI 718Plus ${ }^{\circledR}$ Superalloy," Superalloys 2008, ed. R. Reed, K. Green, P. Caron, T. Gabb, M. Fahrmann, E. Huron, S. Woodward, TMS, 2008, pp. 789-798. 